\title{
Externalizing and internalizing symptoms and coping strategies in young victims of abuse
}

\author{
Juan Manuel Moreno-Manso ${ }^{1}$ (D) $\cdot M^{a}$. Elena García-Baamonde ${ }^{1} \cdot$ Eloísa Guerrero-Barona ${ }^{1} \cdot M^{a}$. José Godoy-Merino ${ }^{1}$. \\ Mónica Guerrero-Molina ${ }^{1}$ • Carlos Barbosa-Torres ${ }^{1}$
}

Accepted: 11 June 2021 / Published online: 1 July 2021

(C) The Author(s) 2021

\begin{abstract}
This research analyses the internalizing and externalizing symptoms and the coping strategies of young victims of abuse. These young people are in residential care under protective measures due to abuse. The participants were 61 youths (32 male and 29 female) between 12 and 17 years of age. Different works of research stress the need for an early identification of the psychopathological symptomatology that these adolescents may present in order to provide an adequate psycho-educational intervention. The relationship between the adolescents' psychopathological symptomatology and the coping strategies and styles they use to resolve problems is studied. It is also analyzed whether internalizing and externalizing problems predict the style and coping strategies of adolescents. Two tests were used: 1. Child and Adolescent Evaluation System (SENA); 2. Adolescent Coping Scales (ACS). The results indicate that young victims of abuse have internalizing and externalizing symptoms. These adolescents are characterized by an unproductive coping style, as well as by the use of coping strategies that are not very functional and ineffective for resolving conflicts. The psychopathological symptomatology is related to and predicts an unproductive coping style, badly adapted to solving daily problems (worrying, blaming oneself, not coping, ignoring the problem, or keeping it to oneself). This research has allowed us to identify the presence of several areas of vulnerability in these young persons which could be playing an important role in their psychosocial maladjustment. The research suggests the design of intervention strategies, for both groups and individuals, aimed at mitigating and modifying the sources of the problems in victims of child abuse.
\end{abstract}

Keywords Child abuse $\cdot$ Psychopathology $\cdot$ Internalizing symptoms $\cdot$ Externalizing symptoms $\cdot$ Coping $\cdot$ Residential care

\section{Introduction}

The primordial function of residential care is to protect children and adolescents who are suffering abuse. The increase in intra-family violence over recent years requires greater therapeutic attention for these adolescents, given that they can manifest internalizing and externalizing symptoms as a consequence of their unprotected situation. Traumatic experiences, such as having suffered abuse, together with separation from the nuclear family, the breaking of parental ties and admittance to a residential care home, can all result in these adolescents becoming a potential risk group for suffering from

Juan Manuel Moreno-Manso

jmmanso@unex.es

1 Department of Psychology, University of Extremadura, Avd. Elvas, s/n, 06006 Badajoz, Spain mental health issues (Alisic et al., 2014; Bal et al., 2003; McLaughlin et al., 2012; McLaughlin \& Sheridan, 2016; MacMillan \& Munn, 2001).

Different works of research have demonstrated the need for an early identification of the psychopathological symptomatology that these adolescents may present in order to provide an adequate psycho-educational response to the emotional and/or behavioral maladjustment that may occur, given that the presence of psychological disorders in children and adolescents in residential care who are victims of abuse is greater than in the general population (Del Valle et al., 2011; Greger et al., 2015; Jozefiak et al., 2016; Simsek et al., 2007).

Several works of research have demonstrated that, among the maladjustments in victims of child abuse, we can find emotional and behavioral problems, resulting in some adolescents presenting inadequate behavior patterns, such as difficulties in controlling anger and aggression, defiant behavior, attention span problems, hyperactivity, anxiety, depression, or somatizations, etc. (Cicchetti \& Toth, 2016; Finkelhor et al., 
2015; Grasso et al., 2016; Madigan et al., 2019; Racine et al., 2020). Similarly, child abuse (particularly sexual abuse) needs to be considered a significant risk factor for both non-suicidal self-injury and suicide attempts (Serafini et al., 2017).

In this sense, several research works have found a greater presence of externalizing problems than internalizing ones (Gearing et al., 2015; Vanschoonlandt et al., 2013). However, other studies have concluded that the internalizing symptoms are more frequent (Jozefiak et al., 2016; Keller et al., 2010), and other works have even found a similar prevalence of both types of symptom (Lehmann et al., 2013; McWey et al., 2010).

On the other hand, the age of the population in residential care over the last few years has been on the increase and these older adolescents manifest ever more severe problems of mental health (Evans et al., 2014; González-García et al., 2017; McMillen et al., 2005). Nevertheless, despite the relevance of the subject, the research works concerning the psychopathological symptomatology of this population continue to be scarce (Mersky et al., 2017; Sainero et al., 2014).

As pointed out by Fong et al. (2018), He et al. (2015) and Martín et al. (2020), the detection of mental health problems in children and adolescents in residential care who have suffered abuse is complex, even more so when it is a question of detecting problems of internalization, as the symptoms are not so evident as those of externalization. This supposes a handicap at the time of having to provide an early, adequate therapeutic response to the mental health problems of these adolescents.

Similarly, the way in which these adolescents cope with the problems they have, at such a vulnerable time of life as adolescence, can lead to an inadequate adaptation to the social context, appearing as difficulties in socialization, of group integration and coexistence (Frydenberg \& Lewis, 2009; Greenberg et al., 2018; Khan \& Deb, 2021; Compas et al., 2001).

Coping strategies can play a mediating role between the adverse life experiences suffered by these adolescents, the personal and social resources they possess to resolve them and the consequences that may derive from their mental health problems (Gartland et al., 2019; Luthar et al., 2015; Masten \& Barnes, 2018). In this sense, some research works have found difficulties in adolescents to adequately deal with social problems, as well as difficulties to adapt to new, everyday situations and to control their behavior and their emotions (Jaffee et al., 2007; Yoon, 2018; Walsh et al., 2010).

Thus, it is vital to determine the relationship between the psychopathological symptomatology of these adolescents and the coping strategies or mechanisms they possess.

In this context, the objectives of the research were: to analyze the presence of internalizing and externalizing symptoms in a sample of young Spanish persons in residential care who were victims of abuse; to study the coping styles and strategies used by these adolescents to resolve their difficulties; to examine the relationship between the psychopathological symptomatology and the coping styles they use; and also to determine the predictive value that the internalizing and externalizing problem has for the coping style they use. We expected these adolescents to manifest internalizing and externalizing symptoms (hypothesis 1). What is more, we expected to encounter an unproductive coping style and strategy for resolving their problems (hypothesis 2). We also expected that the problems of internalization and externalization would be related to the inadequate coping strategies and mechanisms (hypothesis 3). Lastly, we expected the psychopathological symptomatology to act as a predictor of the coping style of the adolescents (hypothesis 4).

\section{Method}

\section{Participants}

61 adolescents who had suffered abuse and who resided in residential care participated in this research. There were 32 males and 29 females between 12 and 17 years of age. The research was carried out in all the residential care centers of the Region of Extremadura (Spain), but privately managed centers were not included. The centers all have similar characteristics as far as the number of minors they attend to is concerned. The average stay in residential care was of 27 months duration. The sample is representative of the population in residential care in Spain (Childhood Observatory, 2019).

The participants were adolescents who were in care due to the renunciation and/or abandonment on the part of the parents; who had suffered physical and/or psychological abuse, sexual abuse and serious physical neglect; or who had been separated from the family due to the impossibility of the carers to carry out their duties to protect the children (serious mental disorder, drug addiction and/or prostitution).

Immigrants were not included in the research given that there could be a supposed important bias due to a lack of knowledge of the language. Also excluded were those adolescents with a diagnosed autistic disorder or mental disability. Those youths who, at the time of the study, were in the process of evaluation or were under emergency protective measures were also excluded from the study.

\section{Procedure}

The research was authorized by the institution that is legally responsible for the adolescents in residential care (Region of Extremadura, Spain). All subjects gave their informed consent for inclusion before they participated in the study. The young persons participated voluntarily in the research. All procedures performed were in 
accordance with the ethical standards of Extremadura University (Registration $\mathrm{N}^{\circ}$ 181/2020) and with the 1964 Helsinki declaration and its later amendments or comparable ethical standards. The instruments were appllied by four evaluators in the residential care centers where the adolescents resided. The evaluators were given prior instruction in the application of the instruments in order to guarantee the validity and reliability of the data collection.

\section{Data Analyses}

We first of all carried out a descriptive analysis of the psychopathological symptomatology and the coping styles and strategies of the adolescents who had suffered abuse; we then carried out Spearman's correlation analysis to analyze the relationship between the adolescents' internalized and externalized problems and the coping styles and strategies that they use; finally, we performed a linear regression analysis to identify whether the psychopathological symptomatology predicts the coping style and strategies of the adolescents. The statistical package SPSS version 25 was used for the statistical treatment of the data.

\section{Measures}

Two instruments were used to evaluate the variables under study:

1. Evaluation System for children and adolescents (SENA) (Fernández-Pinto et al., 2015). This is a test aimed at detecting the presence of internalizing and externalizing symptoms, contextual problems (family, school, friends), areas of vulnerability that may contribute to the start or maintenance of certain problems, and the psychological resources of these adolescents to deal with the difficulties. The reliability has adequate indices. The mean Cronbach's Alpha is between $\alpha=.82$ and $\alpha=.85$ in the scales of samples from the general and clinical populations, respectively, and $\alpha=.93$ in the global indices.

2. Adolescent Coping Scales (ACS) (Frydenberg \& Lewis, 1996). This test evaluates the coping style and strategies of the adolescents. The ACS evaluates 18 strategies that young person's use to cope with problems. These strategies correspond to three coping styles (resolving the problem, in relation to others and unproductive). The general form of the ACS scale of Cronbach's Alpha is $\alpha=.75$. The internal consistency is $\alpha=.92$ for the productive style, $\alpha=.79$ for the unproductive style and $\alpha=.80$ for the style directed towards others.

\section{Results}

We now set out the results obtained from the application of the instruments.

As for the adolescents' psychopathological symptomatology (hypothesis 1), the results concerning the means and standard deviations of the SENA can be seen below in Table 1. As for the normative data of this instrument, the scores are expressed as $\mathrm{T}$ values (the mean is 50 and the standard deviation is 10).

As for the global indices, the scores obtained are above average in the indices for internalizing and externalizing symptoms and contextual problems. In the personal resources index, the score is within the normal range, although the average is a little low.

Table 1 Means and standard deviations of the SENA

\begin{tabular}{|c|c|c|}
\hline & M & $\mathrm{SD}$ \\
\hline \multicolumn{3}{|l|}{ Global Indices } \\
\hline Index of internalizing symptoms & 63.62 & 2.727 \\
\hline Index of externalizing symptoms & 62.98 & 2.579 \\
\hline Index of contextual problems & 63.56 & 3.686 \\
\hline Index of personal resources & 42.39 & 5.318 \\
\hline \multicolumn{3}{|l|}{ Problem Scales } \\
\hline \multicolumn{3}{|l|}{ *Internalizing symptoms } \\
\hline Depression & 52.31 & 4.296 \\
\hline Anxiety & 63.90 & 2.561 \\
\hline Social anxiety & 60.77 & 2.623 \\
\hline Somatic problems & 61.77 & 5.290 \\
\hline Post-traumatic symptomatology & 60.41 & 8.814 \\
\hline Obsessive-Compulsive & 58.16 & 7.156 \\
\hline \multicolumn{3}{|l|}{ *Externalizing symptoms } \\
\hline Attention problems & 64.38 & 4.845 \\
\hline Hyperactivity-impulsiveness & 64.46 & 6.582 \\
\hline Rage control problems & 59.41 & 6.273 \\
\hline Aggression & 58.18 & 7.390 \\
\hline Defiant behavior & 59.30 & 6.839 \\
\hline Antisocial behavior & 60.16 & 5.866 \\
\hline \multicolumn{3}{|l|}{ *Contextual problems } \\
\hline Family problems & 60.48 & 6.949 \\
\hline School problems & 61.23 & 7.921 \\
\hline Problems with companions & 60.89 & 2.944 \\
\hline \multicolumn{3}{|l|}{ Vulnerability scale } \\
\hline Problems controlling emotions & 63.08 & 5.812 \\
\hline Looking for excitement & 56.69 & 9.976 \\
\hline \multicolumn{3}{|l|}{ Personal Resources scales } \\
\hline Self-esteem & 44.08 & 6.440 \\
\hline Integration \& social competence & 43.02 & 5.557 \\
\hline Awareness of the problems & 51.54 & 6.082 \\
\hline
\end{tabular}


As for the Scales of problems, the results indicate above average scores in such internalizing problems as anxiety, social anxiety, somatic complaints, and post-traumatic symptomatology. In the externalizing scales of problems, the highest scores occur in problems of attention and hyperactivity-impulsiveness. Antisocial behavior also has above average scores. In contextual problems, there are difficulties with the family, the school and with companions.

In the vulnerability scale, the aspect that stands out is problems with controlling one's emotions, so this could constitute a risk factor. In the personal resources scale, the levels of selfesteem, social competence and integration and awareness of the problems are within the average range, although the degree of these adolescents' self-esteem and integration is low.

With respect to the coping styles and strategies used by these adolescents to resolve problems (hypothesis 2), the descriptive results of the ACS can be seen in Table 2. As for the normative data, the scores are interpreted as being within the normal range when they are between the values of 50 and 70 .

The results indicate that it is in the unproductive coping style and strategies that adolescents score the highest. We can see that the averages are higher in all the strategies related to this way of trying to cope with problems: worrying, ignoring the problem, not coping, reducing the tension, blaming oneself, having high hopes and keeping it to oneself.

Table 2 Means and standard deviations in the youths' coping styles and strategies

\begin{tabular}{lll}
\hline & M & SD \\
\hline Productive coping style & 38.82 & 8.876 \\
Concentrating on resolving the problem & 40.38 & 10.763 \\
Making an effort and being successful & 36.87 & 8.808 \\
Physical distractions & 54.98 & 8.694 \\
Looking on the bright side & 37.97 & 8.561 \\
Looking for relaxing amusements & 43.56 & 10.072 \\
Unproductive coping style & 68.23 & 10.905 \\
Worrying & 66.69 & 10.051 \\
Ignoring the problem & 63.61 & 12.698 \\
Not coping & 65.97 & 12.898 \\
Reducing tension & 60.34 & 13.329 \\
Blaming oneself & 64.67 & 8.555 \\
Having high hopes & 59.03 & 8.436 \\
Keeping it to oneself & 63.61 & 10.819 \\
Coping style aimed at others & 56.30 & 12.654 \\
Wishing to belong & 40.44 & 6.840 \\
Turning to intimate friends & 36.36 & 6.296 \\
Looking for spiritual support & 37.03 & 10.229 \\
Social action & 41.43 & 10.874 \\
Looking for professional help & 53.30 & 11.793 \\
Looking for social support & 58.13 & 13.735 \\
\hline
\end{tabular}

However, we can also see that all the scores are within the normal range according to the normative data.

As for the productive coping style and strategies, Table 2 shows below average scores in all the coping strategies. Only in the physical distraction strategy is the average higher; however, this is not significant, given that the score continues to be within the average range. We can see how adolescents hardly use such strategies as concentrating on resolving the problem, making an effort and succeeding, concentrating on the positive and looking for relaxing distractions to resolve their difficulties.

Finally, with respect to the coping style and strategies aimed at others, we can see that the scores are below the average range in the strategies of turning to intimate friends, wishing to belong, social action and looking for spiritual support. However, such strategies as looking for professinal help and social support are within the average range. Similarly, the data also show average scores in the coping style aimed at others.

With respect to the relation between the psychopathological symptomatology and the coping styles and strategies of adolescents (hypothesis 3), Table 3 shows the results of Spearman's correlation analysis.

The results show significant correlations between the different coping styles and strategies and the internalizing and externalizing symptoms and the contextual problems of these adolescents.

The productive coping style, aimed at resolving problems, correlates negatively with the internalizing and externalizing symptoms and the contextual problems of these young persons. Thus, there is no productive coping style in these adolescents with internalizing, externalizing and contextual problems.

The data indicate that productive coping strategies such as concentrating on resolving the problem, making an effort and being successful and physical distractions correlate negatively with the presence of internalizing and externalizing problems in adolescents.

As for the unproductive coping style, the data indicate that such strategies as worrying, ignoring the problem, reducing the tension and blaming oneself correlate positively with internalizing problems; while the externalizing problems correlate positively with worrying, reducing the tension, blaming oneself, having high hopes and keeping it to oneself. The contextual problems, however, are related to reducing the tension and blaming oneself.

The coping style aimed at others correlates negatively with the internalizing and externalizing problems. Therefore, there exists no coping style in relation to others for those adolescents with internalizing and externalizing symptoms.

The data indicate that coping strategies aimed at others, such as wishing to belong, looking for professional help and social support, correlate negatively with the internalizing 
Table 3 Correlation analysis between the psychopathological symptomatology and the coping styles and strategies of young victims of abuse

\begin{tabular}{|c|c|c|c|}
\hline & Index of internalizing symptoms & Index of externalizing symptoms & Index of contextual problems \\
\hline & $\rho$ & $\rho$ & $\rho$ \\
\hline Productive coping style &,$- 259^{*}$ &,$- 483^{* *}$ &,$- 321^{*}$ \\
\hline Concentrating on resolving the problem &,$- 277^{*}$ &,$- 374^{* *}$ &,- 207 \\
\hline Making an effort and being successful &,$- 280^{*}$ &,$- 308^{*}$ &,- 134 \\
\hline Physical distractions &,$- 295^{*}$ &,$- 271^{*}$ &, 246 \\
\hline Looking on the bright side & ,199 &,- 223 &,- 102 \\
\hline Looking for relaxing amusements & ,206 &,- 239 &,- 042 \\
\hline Unproductive coping style &,- 084 &,- 007 & ,094 \\
\hline Worrying &, $442^{* *}$ &, $430^{* *}$ &,- 225 \\
\hline Ignoring the problem &, $281^{*}$ & ,202 & ,106 \\
\hline Not coping &,- 140 &, 156 &, 146 \\
\hline Reducing tension &, $686^{* *}$ &, $540^{* *}$ &, $264^{*}$ \\
\hline Blaming oneself &, $542^{* *}$ &, $461^{* *}$ &, $265^{*}$ \\
\hline Having high hopes &, 157 &, $267^{*}$ &,- 194 \\
\hline Keeping it to oneself &,- 203 &, $293^{*}$ & ,196 \\
\hline Coping style aimed at others &,$- 253^{*}$ &,$- 330^{* *}$ &,- 144 \\
\hline Wishing to belong &,$- 266^{*}$ &,- 232 &,- 038 \\
\hline Turning to intimate friends & ,228 &,- 198 &,- 099 \\
\hline Looking for spiritual support &, 160 &,$- 374^{* *}$ &,- 112 \\
\hline Social action & ,146 &,$- 300^{*}$ &,$- 271^{*}$ \\
\hline Looking for professional help &,$- 609^{* *}$ &,$- 592^{* *}$ &,$- 287^{*}$ \\
\hline Looking for social support &,$- 454^{* *}$ &,$- 487^{* *}$ &,- 246 \\
\hline
\end{tabular}

$* p<.05 ; * * p<.01$

problems of adolescents; while social action and looking for spiritual support, professional help and social support correlate negatively with the externalizing problems. Finally, contextual problems correlate negatively with social action and looking for professional help.

Lastly, to identify whether the psychopathological symptomatology of these adolescents can predict the coping styles and strategies (hypothesis 4), we carried out a linear regression analysis (Table 4).

Table 4 shows that the internalizing symptoms of these adolescents can significantly predict an unproductive coping style $(\beta=.25 ; p=.044)$. To be precise, the strategies that predict this style are: worrying $(\beta=.44 ; p=.000)$, ignoring the problem $(\beta=-.28 ; p=.029)$, reducing the tension $(\beta=.68$; $\mathrm{p}=.000)$ and blaming oneself $(\beta=.54 ; \mathrm{p}=.000)$. We can see that this is also true for: physical distraction $(\beta=-.29$; $p=.021)$, wishing to belong $(\beta=.26 ; p=.039)$ and looking for social support $(\beta=-.29 ; p=.021)$.

The data indicate that the externalizing symptoms also significantly predict an unproductive coping style $(\beta=-.48$; $p=.000)$, mainly such strategies as worrying $(\beta=-.43$; $p=.001)$, not coping $(\beta=-.29 ; \mathrm{p}=.021)$, reducing the tension $(\beta=-.54 ; p=.000)$, blaming oneself $(\beta=-.46$; $\mathrm{p}=.000)$, having high hopes $(\beta=-.26 ; p=.038)$ and keeping it to oneself $(\beta=.29 ; p=.022)$. This is also true for physical distraction $(\beta=.27 ; p=.034)$, social action $(\beta=-.30$; $p=.019)$ and looking for social support $(\beta=-.25 ; p=.044)$.

Finally, contextual problems (family, school, and peers) also predict an unproductive coping style $(\beta=-.32$; $p=.012)$. This appears through the strategies of reducing the tension $(\beta=-.26 ; p=.040)$ and blaming oneself $(\beta=-.26$; $p=.039)$. The same is also true of social action $(\beta=-.27$; $p=.035)$.

\section{Discussion}

We can conclude that adolescents who have suffered abuse have internalizing and externalizing symptoms and contextual problems.

With respect to internalizing symptoms, this research shows symptoms of anxiety, social anxiety, somatic complaints, and post-traumatic symptomatology. Worth noting is the presence of symptoms of anxiety, which can be seen through constant worries, fears, nervousness and hyperarousal. Similarly, some adolescents have somatic discomfort related to the symptoms of anxiety. We can also observe symptoms of anxiety related to situations of a social nature, as well 
Table 4 Regression analysis between the psychopathological symptomatology and the coping styles and strategies of young victims of abuse

\begin{tabular}{|c|c|c|c|c|c|c|c|c|c|c|c|c|}
\hline & \multicolumn{4}{|c|}{ Index of internalizing symptoms } & \multicolumn{4}{|c|}{ Index of externalizing symptoms } & \multicolumn{4}{|c|}{ Index of contextual problems } \\
\hline & $\mathrm{R}^{2}$ & $\beta$ & $\mathrm{t}$ & Sig. & $\mathrm{R}^{2}$ & $\beta$ & $\mathrm{t}$ & Sig. & $\mathrm{R}^{2}$ & $\beta$ & $\mathrm{t}$ & Sig. \\
\hline Productive coping style & .007 & -.084 & -.647 & .520 & .000 & -.007 & -.054 & .957 & .009 & .094 & .727 & .470 \\
\hline Concentrating on resolving the problem & .025 & .157 & 1.221 & .227 & .041 & .202 & 1.583 & .119 & .043 & -.207 & -1.629 & .109 \\
\hline Making an effort and being successful & .041 & -.203 & -1.595 & .116 & .011 & .106 & .815 & .418 & .018 & -.134 & -1.041 & .302 \\
\hline Physical distractions & .087 & -.295 & -2376 & .021 & .074 & .271 & 2.165 & .034 & .060 & .246 & 1.948 & .056 \\
\hline Looking on the bright side & .039 & .199 & 1.556 & .125 & .050 & -.223 & -1.755 & .084 & .010 & -.102 & -.787 & .435 \\
\hline Looking for relaxing amusements & .042 & .206 & 1.613 & .112 & .057 & -.239 & -1.890 & .064 & .002 & -.042 & -.324 & .747 \\
\hline Unproductive coping style & .067 & .259 & 2.058 & .044 & .233 & -.483 & -4.236 & .000 & .103 & -.321 & -2.607 & .012 \\
\hline Worrying & .195 & .442 & 3.784 & .000 & .185 & -.430 & -3.656 & .001 & .050 & -.225 & -1.771 & .082 \\
\hline Ignoring the problem & .079 & -.281 & -2.245 & .029 & .041 & .202 & 1.583 & .119 & .011 & .106 & .815 & .418 \\
\hline Not coping & .020 & -.140 & -1.083 & .283 & .087 & -.295 & -2376 & .021 & .021 & .146 & 1.130 & .263 \\
\hline Reducing tension & .471 & .686 & 7.247 & .000 & .291 & -.540 & -4.922 & .000 & .070 & -.264 & -2.104 & .040 \\
\hline Blaming oneself & .293 & .542 & 4.951 & .000 & .213 & -.461 & -3.991 & .000 & .070 & -.265 & -2.113 & .039 \\
\hline Having high hopes & .025 & .157 & 1.221 & .227 & .071 & -.267 & -2.125 & .038 & .037 & -.194 & -1.516 & .135 \\
\hline Keeping it to oneself & .041 & -.203 & -1.595 & .116 & .086 & .293 & 2.355 & .022 & .038 & .196 & 1.533 & .131 \\
\hline Coping style aimed at others & .060 & .246 & 1.948 & .056 & .039 & .199 & 1.556 & .125 & .021 & -.144 & -1.115 & .269 \\
\hline Wishing to belong & .070 & .266 & 2.115 & .039 & .054 & -.232 & -1.832 & .072 & .001 & -.038 & -.295 & .769 \\
\hline Turning to intimate friends & .052 & .228 & 1.802 & .077 & .039 & -.198 & -1.550 & .127 & .010 & -.099 & -.767 & .446 \\
\hline Looking for spiritual support & .026 & .160 & 1.245 & .218 & .020 & -.140 & -1.083 & .283 & .013 & -.112 & -.865 & .391 \\
\hline Social action & .021 & .146 & 1.134 & .262 & .090 & -.300 & -2.415 & .019 & .073 & -.271 & -2.162 & .035 \\
\hline Looking for professional help & .054 & -.232 & -1.832 & .072 & .021 & -.144 & -1.115 & .269 & .002 & -.042 & -.324 & .747 \\
\hline Looking for social support & .087 & -.295 & -2376 & .021 & .067 & .259 & 2.058 & .044 & .061 & -.246 & -1.950 & .056 \\
\hline
\end{tabular}

as fear of being evaluated negatively. Some adolescents have a high score in post-traumatic symptomatology; although this does not necessarily indicate the presence of post-traumatic stress, it should alert us to the need for an evaluation in greater depth, given that manifestations of extreme anxiety can require immediate attention. Bronsard et al. (2011), Jozefiak et al. (2016), Keller et al. (2010) and Lehmann et al. (2013), also found symptoms of anxiety in children and adolescents under protective measures.

As for the externalizing symptoms, this research shows up the presence of disruptive behavior patterns among these young persons which can cause unrest, dissatisfaction, and tension in their principal contexts of socialization. It is worth noting such behavior as hyperactivity and impulsiveness and the symptoms of a lack of attention. These adolescents present a high level of motor activity, accompanied by difficulties to inhibit their behavior (impulsiveness), as well as difficulties to control and maintain their attention while performing tasks or to inhibit interference from irrelevant stimuli. In some adolescents there is also evidence of the presence of antisocial behavior, which becomes apparent through the breaking of the rules of civil co-existence, difficulties in socializing, problems to adapt to the residential care center, attitudes of rejection towards the educational context, teachers and studying, as well as tension and malaise with educators and peers. Several adolescents were observed to have difficulties to integrate in groups, to initiate or maintain relationships with peers or to feel comfortable with them.

Moreno-Manso et al. (2020b), Viezel et al. (2015) and Nikulina and Widom (2013) also found attention deficits, hyperactivity and impulsiveness in adolescents who had suffered abuse during the execution of tasks they had to carry out. Dölitzsch et al. (2016), Gearing et al. (2015), Schmid et al. (2008) and Vanschoonlandt et al. (2013), found a greater externalizing than internalizing problem in the adolescents.

Another aspect worth mentioning in our research is the difficulty these adolescents have to control their emotional reactions. This can be seen through frequent, brusque changes in mood throughout the day. Difficulties were also observed in being able to understand one's own emotions and those of others. In this sense, other studies also found problems of self-control and emotional understanding in victims of child abuse (Heleniak et al., 2016; Moreno-Manso et al., 2020a; Cicognani, 2011; Spratt et al., 2012; Wilson et al., 2011).

The coping style and strategies used by these young persons to resolve their problems are unproductive. The research 
shows the difficulties they must look for effective alternatives to resolve the conflicts that appear in daily life. Many adolescents tend to worry too much and feel themselves to blame and responsible for their problems. They have a negative cognitive style that leads them towards a pessimistic view of life. Other adolescents, however, ignore the problem, refusing to acknowledge its existence and even looking for physical activities to distract themselves. Yet others have high hopes that the problems will go away by themselves, or they keep the problems to themselves, not sharing their difficulties with anyone. In both cases, the coping style is unproductive, the adolescents do not cope with the problem, they do nothing, which immobilizes them, preventing a search for a solution. In some cases, the difficulty to cope with problems or the lack of resources available to these adolescents could be made visible through the presence of externalizing and internalizing symptoms.

Similarly, these young person's hardly use such strategies as wishing to belong or turning to intimate friends to share their problems and look for support in their search for solutions. We can also see that some of these adolescents with very little commitment and involvement in resolving their problems look for others to resolve them through social support or even professional help.

Bierman et al. (2010), Martín et al. (2008), Moreno-Manso et al. (2018) and Vilariño et al. (2013), also found ineffective coping strategies, badly adapted to solving social problems, the demands of the context or new situations.

Finally, our research shows that the internalizing and externalizing problem predicts and is related to an unproductive coping style, badly adapted to solving daily problems (worrying, blaming oneself, not coping, ignoring the problem, or keeping it to oneself). Everything seems to indicate that a greater presence of internalizing and externalizing symptoms means a lower tendency towards productive coping (making an effort and concentrating on searching for a solution) and those oriented towards others (looking for help and support from others to solve problems).

This research has limitations. The results are provided by adolescents who are institutionalized in residential care centers, so the context in which the study is carried out is limited to the sphere of residential care. On the other hand, it has not been possible to analyze the possible influence on the results obtained of the adolescents' length of stay in the centers or the type of abuse. As pointed out by González-García et al. (2017), the longer the stay in residential care, the greater the possibility of the children and adolescents suffering from emotional and behavioral problems; thus the importance of taking this into account for future research. In this sense, Shechory and Sommerfeld (2007) consider that a long stay in a center can increase internalizing problems. Similarly, a longitudinal study would allow the evolution of the internalizing and externalizing symptoms from the start of the stay to be analyzed, as well as the evolution of the coping strategies used to solve problems.

This research has allowed us to identify the presence of several areas of vulnerability in these young persons which could be playing an important role in their psychosocial maladjustment. The possibility of having information concerning the externalizing and internalizing symptoms of these adolescents and their skill in coping with conflicts would allow us to have a comprehensive view of their resources, difficulties, and vulnerabilities.

We have been able to see that the psychological resources available to these adolescents to cope with problems are not adequate as protective factors. The research suggests that, in the design of intervention strategies, for both individuals and groups, aimed at attenuating and modifying the sources of the problems, it is vital to encourage the use of adaptive coping strategies in the complex stage of adolescence, even more so when it is a question of adolescents who have suffered abuse.

Such interventions with adolescents must involve Educators, given the role they exercise in the life of these adolescents during their stay in residential care centers. Holmes et al. (2018) and McLaughlin and Lambert (2017) found a greater adaptation to the intervention when their relationship to the Educators was the adequate one. Similarly, as pointed out by Whittaker et al. (2016), the planning for the intervention will be carried out in real situations to guarantee a better fit with the daily life of these adolescents.

If we take into account the psychopathological symptomatology of these adolescents, as well as the difficulties of integration, social competence and personal and emotional control, the intervention should be aimed at training them in emotional control strategies to regulate their problems (knowing their emotions, identifying the events that make them experience certain emotions, emotional expression and control of their thoughts), an increase in self-esteem (satisfaction with and positive evaluation of themselves), and the development of adequate coping strategies for the situations of social evaluation and interpersonal relationships (training in social competences and skills and the perception of self-efficacy in relationships). Furthermore, for the externalizing symptoms, we would suggest working on strategies in self-control to learn how to improve their attention, impulsiveness, and hyperactivity problems. With respect to the internalizing problems, the intervention would be directed towards reducing their anxiety and showing them how to control their fears through relaxation and desensitization. Similarly, through sessions of psycho-education in the residential care centers, they could learn to manage and cope productively with the problematic behavior patterns that arise in daily life and/or look for support and advice from others when necessary.

Finally, we should point out that, although it is useful to have interventions concerning many of the difficulties characterize them; while working with these adolescents, we must 
keep in mind the abuses they have experienced, the traumatic events they have suffered and the family dynamics they have had to face in their lives (Galán, 2014; Tarren-Sweeney, 2017). Intervention concerning such experiences is essential, given that they may, at an adult age, act as medium to long term risk factors for such affective disorders as anxiety, food related behavior, dissociative, substance addiction, personality, suicidal and self-injury behavior, or problems in interpersonal relations, etc. (Dvir et al., 2014).

Funding Open Access funding provided thanks to the CRUE-CSIC agreement with Springer Nature.

Data Availability All data generated or analyzed during this study are included in this published article.

\section{Declarations}

Conflict of Interest On behalf of all authors, the corresponding author states that there is no conflict of interest.

Ethical Approval All procedures performed in studies involving human participants were in accordance with the ethical standards of the institutional and/or national research committee and with the 1964 Helsinki declaration and its later amendments or comparable ethical standards.

Informed Consent Informed consent was obtained from all individual participants included in the study.

Open Access This article is licensed under a Creative Commons Attribution 4.0 International License, which permits use, sharing, adaptation, distribution and reproduction in any medium or format, as long as you give appropriate credit to the original author(s) and the source, provide a link to the Creative Commons licence, and indicate if changes were made. The images or other third party material in this article are included in the article's Creative Commons licence, unless indicated otherwise in a credit line to the material. If material is not included in the article's Creative Commons licence and your intended use is not permitted by statutory regulation or exceeds the permitted use, you will need to obtain permission directly from the copyright holder. To view a copy of this licence, visit http://creativecommons.org/licenses/by/4.0/.

\section{References}

Alisic, E., Zalta, A. K., van Wesel, F., Larsen, S. E., Hafstad, G. S., Hassanpour, K., \& Smid, G. E. (2014). Rates of post-traumatic stress disorder in trauma-exposed children and adolescents: A meta-analysis. The British Journal of Psychiatry, 204, 335-340. https:// doi.org/10.1192/bjp.bp.113.131227.

Bal, S., Crombez, G., Van Oost, P., \& De Bourdeadhuij, I. (2003). The role of social support in well-being and coping with the self-reported stressful events in adolescents. Child Abuse \& Neglect, 27, 13771395. https://doi.org/10.1016/j.chiabu.2003.06.002.

Bierman, K. L., Torres, M. M. \& Schofield, H. T. (2010). Developmental factors related to the assessment of social skills. En D. W. Nangle, D. J. Hansen, C. A. Erdley \& P. J. Norton (Eds.). Practitioner's guide to empirically based measures of social skills. Springer.
Bronsard, G., Lançon, C., Loundou, A., Auquier, P., Rufo, M., \& Siméoni, M. C. (2011). Prevalence rate of DSM mental disorders among adolescents living in residential group homes of the French child welfare system. Children and Youth Services Review, 33, 1886-1890. https://doi.org/10.1016/j.childyouth.2011.05.014.

Cicchetti, D., \& Toth, S. L. (2016). Child maltreatment and developmental psychopathology: A multilevel perspective. In D. Cicchetti (Ed.), Developmental psychopathology: Maladaptation and psychopathology (p. 457-512). John Wiley \& Sons, Inc. https://doi.org/10.1002/ 9781119125556.devpsy311.

Cicognani, E. (2011). Coping strategies with minor stressors in adolescence: Relationships with social support, self-efficacy, and psychological well-being. Journal of Applied Social Psychology, 41(3), 559-578. https://doi.org/10.1111/j.1559-1816.2011.00726.x.

Compas, B. E., Connor-Smith, J. K., Saltzman, H., Thomsen, A. H., \& Wadsworth, M. E. (2001). Coping with stress during childhood and adolescence: Problems, progress, and potential in theory and research. Psychological Bulletin, 127(1), 87-127. https://doi.org/10. 1037/0033-2909.127.1.87.

Del Valle, J. F., Sainero, A., \& Bravo, A. (2011). Salud mental de menores en acogimiento residencial. Junta de Extremadura.

Dölitzsch, C., Kölch, M., Fegert, J. M., Schmeck, K., \& Schmid, M. (2016). Ability of the child behavior checklist-dysregulation profile and the youth self report-dysregulation profile to identify serious psychopathology and association with correlated problems in highrisk children and adolescents. Journal of Affective Disorders, 205, 327-334. https://doi.org/10.1016/j.jad.2016.08.010.

Dvir, Y., Ford, J. D., Hill, M., \& Frazier, J. A. (2014). Childhood maltreatment, emotional dysregulation and psychiatric comorbidities. Harvard Review of Psychiatry, 22, 149-161. https://doi.org/10. 1097/HRP.0000000000000014.

Evans, S. E., Steel, A. L., Watkins, L. E., \& DiLillo, D. (2014). Childhood exposure to family violence and adult trauma symptoms: The importance of social support from a spouse. Psychological Trauma: Theory, Research. Practice and Policy, 6, 527-536. https://doi.org/10.1037/a0036940.

Fernández-Pinto, I., Santamaría, P., Sánchez-Sánchez, F., Carrasco, M.A. \& del Barrio, V. (2015). SENA. Sistema de Evaluación en Niños y Adolescentes. Manual de aplicación, corrección e interpretación. TEA Ediciones.

Finkelhor, D., Shattuck, A., Turner, H., \& Hamby, S. (2015). A revised inventory of adverse childhood experiences. Child Abuse \& Neglect, 48, 13-21. https://doi.org/10.1016/j.chiabu.2015.07.011.

Fong, H., Alegria, M., Bair-Merritt, M. H., \& Beardslee, W. (2018). Factors associated with mental health services referrals for children investigated by child welfare. Child Abuse \& Neglect, 79, 401-412. https://doi.org/10.1016/j.chiabu.2018.01.020.

Frydenberg, E. \& Lewis, R. (1996). Manual: ACS. Escalas de Afrontamiento para Adolescentes. TEA Ediciones.

Frydenberg, E., \& Lewis, R. (2009). Relations among well-being, avoidant coping, and active coping in a large simple of Australian adolescents. Psychological Reports, 104, 745-758. https://doi.org/ 10.2466/PR0.104.3.745-758.

Galán, A. (2014). Tratamiento psicológico de niños y adolescentes en acogimiento residencial. Aportaciones a un campo específico de intervención. Papeles del Psicólogo, 35(3), 201-209.

Gartland, D., Riggs, E., Muyeen, S., Giallo, R., Afifi, T. O., MacMillan, H., MacMillan, H., Herrman, H., Bulford, E., \& Brown, S. J. (2019). What factors are associated with resilient outcomes in children exposed to social adversity? A systematic review. BMJ Open, 9(4), e024870. https://doi.org/10.1136/bmjopen-2018-024870.

Gearing, R. E., Schwalbe, C. S. J., MacKenzie, M. J., Brewer, K. B., \& Ibrahim, R. W. (2015). Assessment of adolescent mental health and behavioral problems in institutional care: Discrepancies between staff-reported CBCL scores and adolescents-reported YSR scores. Administration and Policy in Mental Health and Mental Health 
Services Research, 42, 279-287. https://doi.org/10.1007/s10488014-0568-y.

González-García, C., Bravo, A., Arruabarrena, I., Martín, E., Santos, I., \& Del Valle, J. F. (2017). Emotional and behavioral problems of children in residential care: Sreening detection and referrals to mental health services. Children and Youth Services Review, 73, 100-106. https://doi.org/10.1016/j.childyouth.2016.12.011.

Grasso, D., Dierkhising, C., Branson, C., Ford, J., \& Lee, R. (2016). Developmental patterns of adverse childhood experiences and current symptoms and impairment in youth referred for trauma-specific services. Journal of Abnormal Child Psychology, 44(5), 871-886. https://doi.org/10.1007/s10802-015-0086-8.

Greenberg, D. M., Baron-Cohen, S., Rosenberg, N., Fonagy, P., \& Rentfrow, P. J. (2018). Elevated empathy in adults following childhood trauma. PLoS One, 13(10), e0203886. https://doi.org/10.1371/ journal.pone.0203886.

Greger, H. K., Myhre, A. K., Lydersen, S., \& Jozefiak, T. (2015). Previous maltreatment and present mental health in a high-risk adolescent population. Child Abuse \& Neglect, 45, 122-134. https:// doi.org/10.1016/j.chiabu.2015.05.003.

He, A. S., Lim, C. S., Lecklitner, G., Olson, A., \& Traube, D. E. (2015). Interagency collaboration and identifying mental health needs in child welfare: Findings from Los Angeles country. Children and Youth Services Review, 53, 39-43. https://doi.org/10.1016/j. childyouth.2015.03.013.

Heleniak, C., Jenness, J. L., Vander, A., McCauley, E., \& McLaughlin, K. A. (2016). Childhood maltreatment exposure and disruptions in emotion regulation: A Transdiagnostic pathway to adolescent internalizing and externalizing psychopathology. Cognitive Therapy and Research, 40, 394-415. https://doi.org/10.1007/s10608-015-9735$\mathrm{z}$.

Holmes, L., Connolly, C., Mortimer, E., \& Hevesi, R. (2018). Residential group care as a last resort: Challenging the rhetoric. Residential Treatment for Children \& Youth, 35(3), 209-224. https://doi.org/ 10.1080/0886571X.2018.1455562.

Jaffee, S. R., Caspi, A., Moffitt, T. E., Polo-Tomas, M., \& Taylor, A. (2007). Individual, family, and neighborhood factors distinguish resilient from non-resilient maltreated children: A cumulative stressors model. Child Abuse \& Neglect, 31(3), 231-253. https:// doi.org/10.1016/j.chiabu.2006.03.011.

Jozefiak, T., Kayed, N. S., Rimehaug, T., Wormdal, A. K., Brubakk, A. M., \& Wichstrøm, L. (2016). Prevalence and comorbidity of mental disorders among adolescents living in residential youth care. European Child and Adolescent Psychiatry, 25, 33-47. https://doi. org/10.1007/s00787-015-0700-x.

Keller, T. E., Salazar, A. M., \& Courtney, M. E. (2010). Prevalence and timing of diagnosable mental health, alcohol, and substance use problems among older adolescents in the child welfare system. Children and Youth Services Review, 32(4), 626-634. https://doi. org/10.1016/j.childyouth.2009.12.010.

Khan, A., \& Deb, A. (2021). Family as a source of risk and resilience among adults with a history of childhood adversity. Children and Youth Services Review, 121, 105897. https://doi.org/10.1016/j. childyouth.2020.105897.

Lehmann, S., Havik, O. E., Havik, T., \& Heiervang, E. R. (2013). Mental disorders in foster children: A study of prevalence, comorbidity and risks factors. Journal of Child and Adolescent Psychiatric and Mental Health, 7, 39. https://doi.org/10.1186/1753-2000-7-39.

Luthar, S., Crossman, E., \& Small, P. (2015). Resilience and adversity. In R. Lerner (Ed.). Handbook of child psychology and developmental science (pp. 247-286) ( $7^{\text {th }}$ ed.). John Wiley \& Sons, Inc.

MacMillan, H., \& Munn, C. (2001). The sequelae of child maltreatment. Current Opinion in Psychiatry, 14(4), 325-331. https://doi.org/10. 1097/00001504-200107000-00015.

Madigan, S., Cyr, C., Eirich, R., Fearon, R. M. P., Ly, A., Rash, C., Poole, J. C., \& Alink, L. R. A. (2019). Testing the cycle of maltreatment hypothesis: Meta-analytic evidence of the intergenerational transmission of child maltreatment. Development and Psychopathology, 31(1), 23-51. https://doi.org/10.1017/ S0954579418001700.

Martín, E., González-García, C., Del Valle, J., \& Bravo, A. (2020). Detection of behavioral and emotional disorders in residential child care: Using a multi-informant approach. Children and Youth Services Review, 108, 104588. https://doi.org/10.1016/j. childyouth.2019.104588.

Martín, E., Torbay, A. \& Rodríguez, T. (2008). Cooperación familiar y vinculación del menor con la familia en los programas de acogimiento residencial. Anales de Psicología, 24, 25-32. http:// revistas.um.es/analesps/article/view/31681

Masten, A. S., \& Barnes, A. J. (2018). Resilience in children: Developmental perspectives. Children (Basel), 5(7), 98. https:// doi.org/10.3390/children5070098.

McLaughlin, K. A., Green, J. G., Gruber, M. J., Sampson, N. A., Zaslavsky, A. M., \& Kessler, R. C. (2012). Childhood adversities and first onset of psychiatric disorders in a national sample of US adolescents. Archives of General Psychiatry, 69(11), 1151-1160. https://doi.org/10.1001/archgenpsychiatry.2011.2277

McLaughlin, K. A., \& Lambert, H. K. (2017). Child trauma exposure and psychopathology: Mechanisms of risk and resilience. Current Opinion in Psychology, 14, 29-34. https://doi.org/10.1016/j. copsyc.2016.10.004.

McLaughlin, K. A., \& Sheridan, M. A. (2016). Beyond cumulative risk: A dimensional approach to childhood adversity. Current Directions in Psychological Science, 25(4), 239-245. https://doi.org/10.1177/ 0963721416655883.

McMillen, J. C., Zima, B. T., Scott, L. D., Auslander, W. F., Munson, M. R., Ollie, M. T., \& Spitznagel, E. L. (2005). Prevalence of psychiatric disorders among older youths in the foster care system. Journal of the American Academy of Child and Adolescent Psychiatry, 44(1), 88-95. https://doi.org/10.1097/01.chi.0000145806.24274. d2.

McWey, L. M., Cui, M., \& Pazdera, A. L. (2010). Changes in externalizing and internalizing problems of adolescents in Foster Care. Journal of Marriage and Family, 72(5), 1128-1140. https://doi. org/10.1111/j.1741-3737.2010.00754.x.

Mersky, J. P., Janczewski, C. E., \& Topitzes, J. (2017). Rethinking the measurement of adversity. Child Maltreatment, 22(1), 58-68. https://doi.org/10.1177/1077559516679513.

Moreno-Manso, J. M., García-Baamonde, M. E., Blázquez-Alonso, M., Guerrero-Barona, E., \& Godoy-Merino, M. J. (2018). Empathy and coping strategies in youths subject to protection measures. Children and Youth Services Review, 93, 100-107. https://doi.org/10.1016/j. childyouth.2018.07.011.

Moreno-Manso, J.M., García-Baamonde, M.E., de la Rosa Murillo, M., Blázquez-Alonso, M., Guerrero-Barona, E., García-Gómez, A. (2020a). Differences in executive functions in minors suffering physical abuse and neglect. Journal Interpersonal Violence, (published online). https://doi.org/10.1177/0886260520944528, 088626052094452.

Moreno-Manso, J. M., García-Baamonde, M. E., Guerrero-Barona, E., Godoy-Merino, M. J., Bueso-Izquierdo, N., \& Guerrero-Molina, M. (2020b). Emotional, behavioural and executive functioning problems in children in residential care. International Journal of Environmental Research and Public Health, 17, 3596. https://doi. org/10.3390/ijerph17103596.

Nikulina, V., \& Widom, C. S. (2013). Child maltreatment and executive functioning in middle adulthood: A prospective examination. Neuropsychology, 27(4), 417-427. https://doi.org/10.1037/ a0032811.

Observatorio de la Infancia (2019). Boletín de datos estadísticos de medidas de protección a la infancia. Boletín número 21. Datos 2018. Ministerio de Sanidad, Consumo y Bienestar Social. 
Racine, N., Eirich, R., Dimitropoulos, G., \& Hartwick, C. (2020). Development of trauma symptoms following adversity in childhood: The moderating role of protective factors. Child Abuse \& Neglect, 101, 104375. https://doi.org/10.1016/j.chiabu.2020. 104375.

Sainero, A., Bravo, A., \& Del Valle, J. F. (2014). Examining needs and referrals to mental health services for children in residential care in Spain: An empirical study in an autonomous community. Journal of Emotional and Behavioral Disorders, 22, 16-26. https://doi.org/10. $1177 / 1063426612470517$.

Serafini, G., Canepa, G., Adavastro, G., Nebbia, J., Belvederi Murri, M., Erbuto, D., Pocai, B., Fiorillo, A., Pompili, M., Flouri, E., \& Amore, M. (2017). The relationship between childhood maltreatment and non-suicidal self-injury: A systematic review. Frontiers in Psychiatry, 8, 149. https://doi.org/10.3389/fpsyt.2017.00149.

Shechory, M., \& Sommerfeld, E. (2007). Attachment style, home-leaving age and behavioral problems among residential care children. Child Psychiatry and Human Development, 37(4), 361-373. https://doi. org/10.1007/s10578-007-0051-z.

Simsek, Z., Erol, N., Öztop, D. y Münir, K. (2007). Prevalence and predictors of emotional and behavioral problems reported by teachers among institutionally reared children and adolescents in turkish orphanages compared with community controls. Children and Youth Services Review, 29 (7), 883-899. https://doi.org/10. 1016/j.childyouth.2007.01.004.

Schmid, M., Goldbeck, L., Nuetzel, J., \& Fegert, J. M. (2008). Prevalence of mental disorders among adolescents in German youth welfare institutions. Child and Adolescent Psychiatry and Mental Health, 2, 2. https://doi.org/10.1186/1753-2000-2-2.

Spratt, E. G., Friedenberg, S., LaRosa, A., De Bellis, M. D., Macias, M. M., Summer, A. P., Hulsey, T. C., Runyan, D. K., \& Brady, K. T. (2012). The effects of early neglect on cognitive, language, and behavioral functioning in childhood. Psychology, 3(2), 175-182. https://doi.org/10.4236/psych.2012.32026.

Tarren-Sweeney, M. (2017). Rates of meaningful change in the mental health of children in long-term out-of-home care: A seven- to nine- year prospective study. Child Abuse \& Neglect, 72, 1-9. https://doi. org/10.1016/j.chiabu.2017.07.002.

Vanschoonlandt, F., Vanderfaeillie, J., Van Holen, F., De Maeyer, S., \& Robberechts, M. (2013). Externalizing problems in young foster children: Prevalence rates, predictors and service use. Children and Youth Services Review, 35(4), 716-724. https://doi.org/10. 1016/j.childyouth.2013.01.015.

Viezel, K., Freer, B. D., Castillo, J., \& Lowell, A. (2015). Cognitive abilities of maltreated children. Psychology in the Schools, 52(1), 92-106. https://doi.org/10.1002/pits.21809.

Vilariño, M., Amado, B., \& Alves, C. (2013). Menores infractores: un estudio de campo de los factores de riesgo. Anuario de Psicología Jurídica, 23(1), 39-45. https://doi.org/10.5093/aj2013a7.

Walsh, K., Fortier, M. A. y DiLillo, D. (2010). Adult coping with childhood sexual abuse: A theoretical and empirical review. Aggression and Violent Behavior, 15, 1-13. https://doi.org/10.1016/j.avb.2009. 06.009 .

Wilson, K. R., Hansen, D. J., \& Li, M. (2011). The traumatic stress response in child maltreatment and resultant neuropsychological effects. Aggression and Violent Behavior, 16, 87-97. https://doi. org/10.1016/j.avb.2010.12.007.

Whittaker, J. K., Holmes, L., Del Valle, J. F., Ainsworth, F., Andreassen, T., Anglin, J., et al. (2016). Therapeutic residential care for children and youth: A consensus statement of the international work group on therapeutic residential care. Residential Treatment for Children \& Youth, 33(2), 89-106.

Yoon, S. (2018). Fostering resilient development: Protective factors underlying externalizing trajectories of maltreated children. Journal of Child and Family Studies, 27, 443-452. https://doi.org/10.1007/ s10826-017-0904-4.

Publisher's Note Springer Nature remains neutral with regard to jurisdictional claims in published maps and institutional affiliations. 